\title{
Powder from chickling vetch valves in the production of functional biscuits
}

\author{
A.S. Jaboeva ${ }^{1,}$, Z.S. Dumanisheva ${ }^{1}$, A.Ch. Toguzaeva $^{1}, A . A$. Shiritov ${ }^{1}$, and A.D. Thaitlov ${ }^{1}$ \\ ${ }^{1}$ FSBEI HE Kabardino-Balkarian State Agrarian University named after V.M. Kokov, Nalchik, \\ Russia
}

\begin{abstract}
Currently, it is necessary to search for non-traditional sources of plant raw materials characterized by a high content of indigestible polysaccharides having a beneficial effect on human body functions. One of the rich sources of high-molecular carbohydrates is the chickling vetch valves. The use of a new type of raw material in food production will expand the range of functional food products. The technology of powder from chickling vetch valves is developed, its organoleptic quality indicators are determined and the period of storage in warehouse premises is set. Based on the results of the study of the chemical composition of the powder, it was found that it is a valuable source of fiber, lignin, hemicellulose and pectin substances. It was found that when the powder is introduced into the recipe of biscuits in the amount of 1.1-2.2\% by weight of flour, the best organoleptic and physico-chemical quality indicators of finished products are achieved. It was found that when consuming $100 \mathrm{~g}$ of the developed products, the human body's need for dietary fiber is met by $18.3-23.2 \%$.
\end{abstract}

\section{Introduction}

Due to the deterioration of the environmental situation, an increase in the number of stressful situations, and a decrease in immunity to many pathogens, dietary fibers should be included in the human diet, which are physiologically important components of food that prevent many diseases of the human body [1].

Dietary fiber helps to remove the "harmful" fraction of cholesterol from the body, which is important in cases of impaired fat metabolism, atherosclerosis, hypertension, and coronary heart disease; regulates the level of glucose and insulin in the blood; removes heavy metals, radionuclides, and toxic substances; improves intestinal peristalsis [2]. Fermentation products of dietary fiber - volatile fatty acids are absorbed in the intestines and serve as a source of energy, providing about four percent of the total energy balance of the body. The energy generated as a result of anaerobic fermentation of fibrous structures is used by the microflora of the colon, helping to maintain the intestinal biocenosis. Insufficient intake of dietary fiber in the intestines contributes to an increase in the number of anaerobes and spore-bearing bacteria [3].

Plant-based raw materials play an important role in the development of food products

\footnotetext{
*Corresponding author: tpop_kbr@mail.ru
} 
enriched with dietary fiber. Along with the use of traditional sources of dietary fiber, it is necessary to search for new little-known types of plant raw materials, which include highmolecular carbohydrates that are characterized by resistance to digestion and assimilation in the gastrointestinal tract [4]. One of these sources is the chickling vetch valves, which are characterized by a significant content of indigestible polysaccharides. The search for information about ways to process the chickling vetch valves or use them in food production did not give a positive result. The lack of experimental data on the effect of chickling vetch valves and their processed products on the chemical composition and quality indicators of various food groups, including flour confectionery products, does not allow creating innovative technologies for competitive products that cover the physiological needs of the human body in essential nutrients [5].

Despite numerous studies of domestic and foreign scientists in the development of flour confectionery products produced using various plant materials and their derivatives, increase of production volumes of functional purpose food due to the involvement of additional little-known raw materials with high nutritional value into the food circulation, is relevant.

The relevance of the chosen research direction is confirmed by the fact that the obtained results can be used to implement the state program "Strategy of improvement of quality food products in Russia up to 2030", according to which the integrated use of plant raw material resources is provided on the basis of rational combination of traditional and nontraditional raw materials, as well as the "creation of technologies for the production of qualitatively new food products with a directed change in the chemical composition corresponding to the needs of the human body, including products for the prevention of various diseases and strengthening the protective functions of the body."

The objective of the work was to provide a scientific justification for the use of powder obtained from chickling vetch valves in the production of functional biscuits.

\section{Materials and methods}

The objects of research: powder obtained from chickling vetch valves of "Mramornaya" variety; dough for biscuits made with yeast and products baked from it (control); dough for biscuits made with yeast using powder from chickling vetch valves and products baked from it (test samples).

The following ingredients were used in the production of biscuits: high-grade wheat flour - GOST 26574-2017 [6], white sugar - GOST 33222-2015 [7], edible salt - GOST R 51574-2018 [8], pressed baking yeast - GOST R 54731-2011 [9], butter - GOST 322612013 [10], drinking water - SanPiN 2.1.4.1074-01 [11].

Experimental studies were carried out in the research and technological laboratories of the Department of "Technology of food products and chemistry" of the KabardinoBalkarian State Agrarian University named after V. M. Kokov".

In the chickling vetch valves weight fraction of dry substances was determined - by two-step method [12], fiber - by Henneberg and Stoman method [13], lignin - by GameKnolle method [14], hemi-cellulose - by the number of sugars resulting from acid hydrolysis of the residue after extraction of water-soluble substances [15], pectin - by titrimetric method [16].

The weight fraction of moisture in flour was determined according to GOST 9404-88 [17], acidity - according to GOST 27493-87 [18], the weight fraction of raw gluten and its quality - according to GOST 27839-2013 [ 19], the falling number - according to GOST 27676-88 [20].

Biscuits were produced in the laboratory and in production conditions. The effect of the powder obtained from chickling vetch on the quality of products was judged by 
organoleptic and physico-chemical parameters. The weight fraction of moisture in biscuits was determined according to GOST 5900-2014 [21], the acidity and wetness of products according to GOST 5898-87 [22] and GOST 10114-80 [23], respectively. The shape, surface, color, taste, smell, and appearance in the fracture of the experimental samples were evaluated by the sensory method with a 5-point scale developed at the Department of "Technology of food products and chemistry" of the Kabardino-Balkarian SAU (Table 1).

Table 1. Scale of organoleptic assessment of the quality of biscuits produced with powder from chickling vetch valves

\begin{tabular}{|c|c|c|c|c|}
\hline \multirow{2}{*}{ Indicator } & \multicolumn{4}{|c|}{ Organoleptic quality assessment, in points } \\
\hline & excellent & good & satisfactory & unsatisfactory \\
\hline 1 & 2 & 3 & 4 & 5 \\
\hline \multirow[t]{2}{*}{ Shape } & \multicolumn{2}{|c|}{$\begin{array}{l}\text { Regular (rectangular shape), } \\
\text { corresponding to this name, } \\
\text { the edges are smooth, without } \\
\text { dents and deformations. The } \\
\text { biscuits must be whole }\end{array}$} & $\begin{array}{l}\text { Correct, the edges } \\
\text { are not smooth } \\
\text { enough, slight } \\
\text { deformation, there } \\
\text { are products with } \\
\text { tears, broken }\end{array}$ & $\begin{array}{l}\text { There are dents, } \\
\text { deformations, } \\
\text { uneven edges, } \\
\text { broken cookies, } \\
\text { with tears }\end{array}$ \\
\hline & $5-4$ & 3.5 & $3-2.5$ & less than 2 \\
\hline \multirow[t]{2}{*}{ Surface } & \multicolumn{2}{|c|}{$\begin{array}{l}\text { Smooth and even, with } \\
\text { punctures, without spots and } \\
\text { foreign inclusions }\end{array}$} & $\begin{array}{l}\text { Insufficiently } \\
\text { smooth and even, } \\
\text { products with } \\
\text { bubbles, with } \\
\text { indistinct } \\
\text { punctures }\end{array}$ & $\begin{array}{l}\text { Rough, indistinct } \\
\text { punctures, } \\
\text { presence of } \\
\text { inclusions, crumbs }\end{array}$ \\
\hline & $5-4$ & $3.5-2.5$ & $1.5-2$ & less than 1 \\
\hline \multirow[t]{2}{*}{$\begin{array}{l}\text { Color, taste and } \\
\text { smell }\end{array}$} & \multicolumn{2}{|c|}{$\begin{array}{l}\text { Uniform, from light yellow to } \\
\text { light brown. Lower side may } \\
\text { be darker or lighter than the } \\
\text { upper side. } \\
\text { Taste and smell of biscuits. }\end{array}$} & $\begin{array}{l}\text { Color is not } \\
\text { uniform enough. } \\
\text { Taste is typical for } \\
\text { biscuits, but the } \\
\text { smell is weakly } \\
\text { expressed }\end{array}$ & $\begin{array}{l}\text { Burnt or too pale. } \\
\text { Foreign taste and } \\
\text { smell (rancidity, } \\
\text { moldiness) }\end{array}$ \\
\hline & $14-15$ & $13.5-11$ & $10-9$ & less than 9 \\
\hline \multirow[t]{2}{*}{$\begin{array}{l}\text { Appearance at } \\
\text { break }\end{array}$} & \multicolumn{2}{|c|}{$\begin{array}{l}\text { Uniformly porous, without } \\
\text { traces of undermixing, } \\
\text { without foreign inclusions } \\
\text { and hollows, baked }\end{array}$} & $\begin{array}{l}\text { Insufficiently } \\
\text { uniform porosity, } \\
\text { presence of } \\
\text { hollows and } \\
\text { undermixing, but } \\
\text { within acceptable } \\
\text { limits }\end{array}$ & $\begin{array}{c}\text { Foreign inclusions, } \\
\text { traces of } \\
\text { undermixing }\end{array}$ \\
\hline & $6-5$ & $5-3$ & $1.5-2.5$ & less than 2.5 \\
\hline Total: & $30-28$ & $25-20$ & $17-15$ & less than 15 \\
\hline
\end{tabular}

\section{Results and discussion}

Powder from chickling vetch was produced in industrial production on the basis of Nalchik cannery LLC (city of Nalchik, the Kabardino-Balkarian Republic). The 
technological process of powder production consists of the following stages: preparation of raw materials for drying; drying of chickling vetch valves to a residual humidity of $13 \%$; grinding, sieving; dosing and packaging.

At the stage of raw material preparation, the valves were sorted on inspection tables by size and quality, then placed in a vibrating washing machine MMV-1, where they were washed with drinking water at a temperature of $15-18^{\circ} \mathrm{C}$. The prepared material was laid out in a uniform layer on the drying surface of the ISK-40 infrared cabinet and dried at a temperature of $45-50{ }^{\circ} \mathrm{C}$, which ensures maximum preservation of the physiologically functional raw material ingredients. The dried valves were crushed using a JBL feed shredder (Czech Republic), then the resulting powder was purified from impurities through a sifter MPM-230.

Organoleptic evaluation of the quality of the powder from the chickling vetch valves showed that it is a homogeneous fine-dispersed loose mass of golden-brown color, with a slight herbal smell and taste.

At the final stage of the technological process, the powder was packed in $500 \mathrm{~g}$ paper bags using a packaging machine with a weight dispenser "Atlas PAK-VD" and sent for storage in a ventilated warehouse.

To determine the shelf life of the powder obtained from the chickling vetch valves, seven packaging units of products were selected from the produced batch, which were stored in the storage group of the cannery premises at a temperature of $20{ }^{\circ} \mathrm{C}$ and a relative humidity of $70 \%$ for 12 months. The condition of the powdered semi-finished product was evaluated monthly by organoleptic, physico-chemical and microbiological quality indicators. Based on the results of the study, it was found that the permissible shelf life of the powder from chickling vetch at a given temperature and relative humidity is 11 months. Storage of the powder for more than 11 months led to an increase in moisture weight fraction in the product and its caking into lumps.

The study of the qualitative composition and quantitative content of the carbohydrate complex of the powder obtained from valves of the "Mramornaya" variety showed that it is a valuable source of substances that form the basis of dietary fiber: fiber, hemicellulose, lignin and pectins (Fig.1).

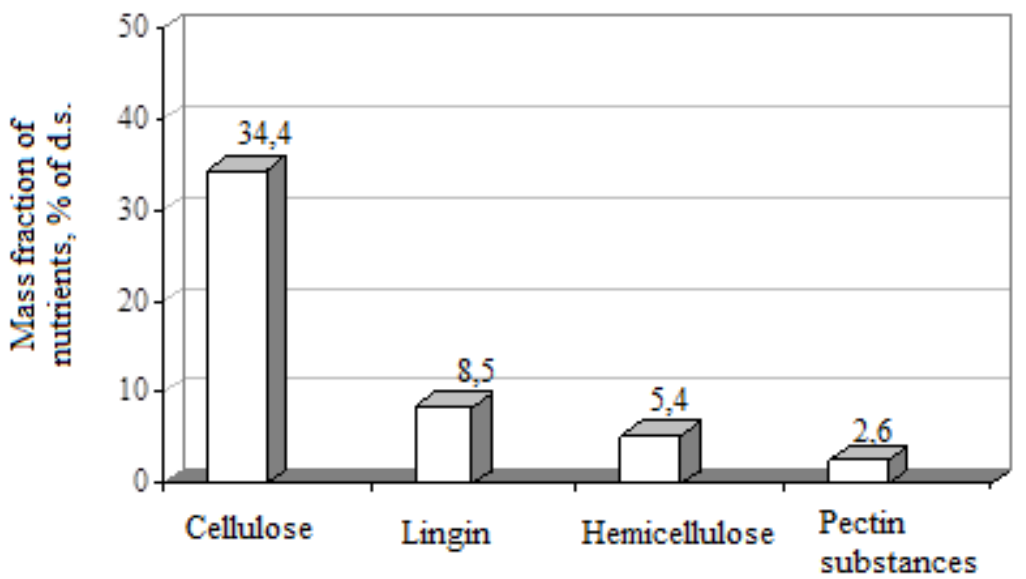

\section{Nutrients fractions}

Fig. 1. Content of dietary fiber in the powder obtained from chickling vetch valves

Among the components of the carbohydrate complex of the powder, fiber prevails, the content of which is higher in comparison with lignin, hemicelluloses and pectin substances 
by $4.0,6.4$ and 13.2 times, respectively.

The results obtained indicate the feasibility of using powder from chickling vetch valves as a source of dietary fiber in the production of functional biscuits.

For the biscuits production, wheat flour of the highest grade was used, humidity $13.8 \%$, acidity 2.0 deg., with weight fraction of raw gluten $30.7 \%, \mathrm{~N}_{\text {def.com }}=74$ pr.units, and fall number of $318 \mathrm{~s}$.

The recipe for yeast biscuits with fat was taken as a control. The dough was kneaded in a straight way. In the production of experimental samples, the powder from chickling vetch valves was introduced when kneading the dough in an amount from 1.0 to $3.0 \%$ by weight of wheat flour in the recipe.

The effect of powder from chickling vetch valves on the baking properties of wheat flour of the highest grade was judged by the results of experimental studies of the gluten content, its quality and fall number. It was found that the introduction of powder into the dough in a dosage from 1.0 to $3.0 \%$ by weight of wheat flour leads to a decrease in the weight fraction of gluten compared to the control by $3.6-14.2 \%$ and an increase in the compression deformation of the FDM by $6.9-17.0 \%$. The study on determination of the effect of the powder from chickling vetch valves on the autolytic activity of flour showed that with the introduction of powder in an amount from 1.0 to $2.5 \%$, the fall number increase compared to the control sample, and then decrease with the introduction of a dosage of powder from 2.6 to $3.0 \%$.

The quality of finished products was determined by organoleptic (shape, surface, color, appearance on the brake, taste and smell) and physico-chemical (weight fraction of moisture, acidity, wetting) indicators. It was found that the best consumer properties of biscuits were achieved by adding $1.1-2.2 \%$ of the powder from chickling vetch to the weight of flour in the recipe. The products had a regular shape, smooth surface, uniform light brown color, pleasant taste and smell characteristic of biscuits. Compared with the control, the humidity and acidity of the test samples were slightly higher, and the wetness was lower by $3.1-7.4 \%$.

Based on the research, recipes and technologies for the production of biscuits using powder from chickling vetch valves, called "Special", were developed.

When determining the chemical composition of the developed products, it was revealed that the use of powder from chickling vetch valves in the production of biscuits leads to an increase in the content of dietary fiber in products.

The degree of coverage of the daily needs of the human body in nutrients when consuming $100 \mathrm{~g}$ of biscuits produced with powder from chickling vetch valves in the amount of 1.1 and $2.2 \%$ by weight of flour compared to the control is higher by 4.7 and $9.7 \%$, respectively (Fig. 2). 


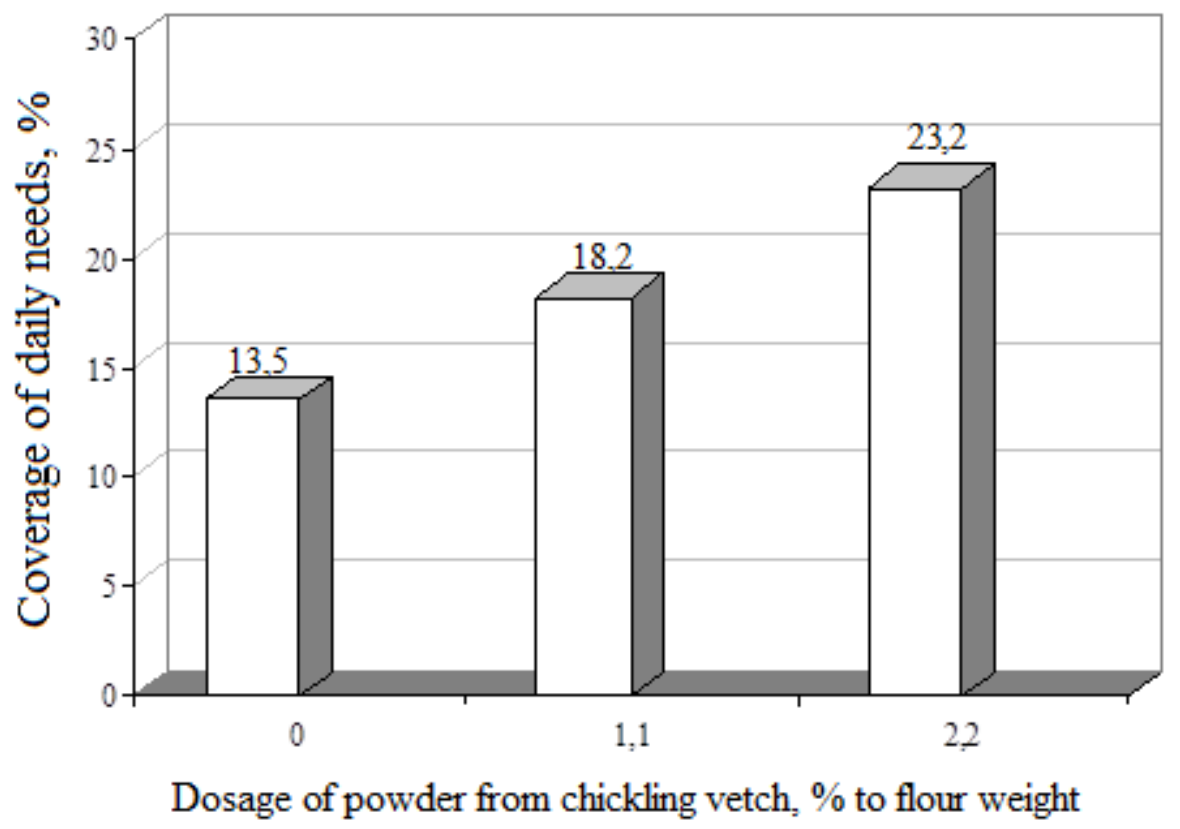

Fig. 2. The effect of the dosage of powder from chickling vetch valves on the degree of coverage of the daily needs of the human body in nutrients when consuming $100 \mathrm{~g}$ of "Special" biscuits

The results of the study indicate that the developed products are enriched with dietary fiber and can be used as a functional food product in the diets of the Russian population.

\section{Conclusions}

For the first time, a comprehensive study was performed that allows to theoretically and experimentally justify the use of powder from chickling vetch valves of the "Mramornaya" variety in the production of functional biscuits.

1. The technological modes of obtaining powder from chickling vetch valves using IR dryer are established, which ensure maximum safety of the functional ingredients of the raw material.

2. The qualitative composition and quantitative content of the carbohydrate complex of the powder from chickling vetch valves were revealed and it was shown that it is a valuable source of indigestible polysaccharides - fiber $(34.4 \mathrm{~g} / 100 \mathrm{~g})$, hemicellulose $(8.5$ $\mathrm{g} / 100 \mathrm{~g})$, lignin $(5.4 \mathrm{~g} / 100 \mathrm{~g})$, pectin substances $(2.6 \mathrm{~g} / 100 \mathrm{~g})$.

3. Based on the results obtained in the study of the carbohydrate composition of the powder from chickling vetch valves, its technological properties, combination with recipe components, scientifically based technological solutions have been developed to ensure the harmonization of organoleptic properties, improve the physical and chemical indicators of the quality and nutritional value of finished products.

4. When consuming $100 \mathrm{~g}$ of "Special" biscuits, the daily need of the human body for dietary fiber is met by $18.3-23.2 \%$, which indicates the functional orientation of the developed products. 


\section{References}

1. E.A. Pyryeva, A.I. Safronov, Nutrition issues, 88(6), 5-11 (2019)

2. H.H. Sharafetdinov, O.A. Plotnikova, A.M. Nazarov et al., Problems of nutrition, 86(6), 56-66 (2017)

3. V.A. Tutelyan, H.H. Sharafetdinov, I.A. Lapik et al., Problems of nutrition, 83(6), 4151 (2014)

4. Norms of physiological needs in energy and food substances for various groups of the population of the Russian Federation, MP 2.3.1.2432-08, (Moscow: Federal service for supervision of consumer rights protection and human welfare, 2008)

5. A.N. Andreeva, Yu.V. Dmitrieva, Scientific journal of NRU ITMO. Series "Processes and devices of food production", 1, 107-117 (2016)

6. GOST 26574-2017 Baking wheat flour, Technical conditions (Moscow: Standartinform, 2017)

7. GOST 33222-2015 White sugar, Technical conditions (Moscow: Standartinform, 2015)

8. GOST R 51574-2018 Food salt, General technical conditions (Moscow: Standartinform, 2018)

9. GOST R 54731-2011 Pressed baking yeast, Technical conditions (Moscow: Standartinform, 2013)

10. GOST 32261-2013 Butter, Technical conditions (Moscow: Standartinform, 2014)

11. SanPiN 2.1.4.1074-01 Drinking water. Hygienic requirements for the water quality of centralized drinking water supply systems. Quality control. Hygienic requirements for ensuring the safety of hot water supply systems (M.: Ministry of Health of Russia, 2002)

12. GOST 32640-2012 Feed, Methods for determining the content of dry matter (M.: Standartinform, 2012)

13. GOST 31675-2012 Feed, Methods for determining the content of crude fiber using intermediate filtration (M.: Standartinform, 2012)

14. GOST 26177-84 Feed, compound feed, Method for lignin determination (M.: Standartinform, 1984)

15. A.I. Ermakov, V.V. Arasimovich, N.P. Yarosh, M.I. Ikonnikova, Methods of biochemical research of plants (L.: Agropromizdat, 1987)

16. GOST 29059-91 Fruit and vegetable derivatives, Titrometric method for determining pectin substances (M.: Standartinform, 2010)

17. GOST 9404-08 Flour and bran, Method for moisture determination (M.: Standartinform, 2007)

18. GOST 27493-87 Flour and bran, Method for determining acidity by magma (M.: Standartinform, 2007)

19. GOST 27839-2013 Wheat flour, Methods for determining the quantity and quality of gluten (M.: Standartinform, 2014)

20. GOST 27676-88 Grain and products of its processing, Method for determining the fall number (M.: Standartinform, 2009)

21. GOST 5900-2014 Confectionery products, Methods for determining moisture and dry substances (M.: Standartinform, 2015) 
22. GOST 5898-87 Confectionery products, Methods for determining acidity and alkalinity (M.: Standartinform, 2012)

23. GOST 10114-80 Flour confectionery products, Method for wetness determination (M.: Standartinform, 2012) 